\title{
Navigating the Academic Labyrinth: Nursing Students' Perspectives
}

\author{
Carnelle Symes, Angela Waigand, Claudia Haddad, Emmanuel Ngwakongnwi \\ University of Calgar, Qatar
}

\begin{abstract}
Understanding students' perceptions of their academic success in an academic post-secondary setting is integral to the development of student success. This article highlights the importance of understanding that student success is complex and culturally linked in a post-secondary setting. This qualitative research study explored the research question: What are the perceived obstacles and motivators to student success in a post-secondary English as a foreign language (EFL) setting in Qatar? In conducting this research, the researchers sought to identify student obstacles and motivators to success in an academic setting. Using a grounded theory approach, cyclical data collection and analysis was completed. Thirty-five participants were involved in interviews and focus groups, which were conducted at an international branch university campus in Qatar. Thematic analysis allowed for the emergence of four broad themes of what accelerates or deters student success. From this thread emerged the two core themes: achieving balance and following goals and passion. Research participants identified that obstacles and motivators have a direct impact on their perceived academic success. These findings have great significance to the academic setting and may inform other academic institutions with a large population of second language nursing students.
\end{abstract}

\section{Introduction}

Overcoming student barriers in learning is crucial to student success. International educators and students are confronted by many unique challenges and opportunities in the English as a Foreign Language (EFL) learning environment. The success of students depends upon many interrelated contextual factors both internal and external [2], which lead to challenges and opportunities. We were interested in studying how students define their own success in the academic institution where they study and what they identify as contributors to this success

\section{Literature review}

A preliminary review of the literature revealed several themes related to academic success and highlighted the need for further research within the context of the Middle East. A total of 306 articles from six nursing, medical, and education focused databases were searched in the preliminary literature review. Sixty-six articles were ultimately chosen for deeper analysis. These articles were divided into themes which were used to inform our initial research proposal and ethics application.

The literature revealed that students studying in a culturally foreign environment face many challenges that could hinder their academic success. A survey of students in the United Arab Emirates indicated that students believed their level of English proficiency was a determining factor in their level of academic success [12]. The findings of two studies revealed that international students in English-speaking countries struggle with completing essay examinations and taking notes due to the limited language proficiency $[6,13]$. Students also felt fearful to communicate with native speakers and felt that this was a barrier in their academic and daily life [13]. Results of a study of nursing students whose first language is not English found that students felt they were discriminated against in their clinical environments, which had a negative impact on their learning [14].

Another factor affecting student success is the academic environment. This includes differences between teaching and learning styles $[6,15]$ and instructors' lack of experience working with English as a second language (ESL) students [3, 14]. An instructors' personality may also affect students' success [3]. In their qualitative study, Bolderston, Palmer, Flanagan, and McParland found that English as a second language (ESL) students responded best to instructors who were open and friendly. The opportunity to contribute to classroom discussion may also impact learning. Harb and Al-sharwi examined factors that affect business students in the United Arab Emirates. They found that active class 
participation positively affects student learning, particularly for female students. They also found a correlation between the physical environment and student success. The physical environment of an institution may increase the likelihood that students would spend more time at on campus and thus focus more on their studies, consequently leading to greater academic achievement [12].

Academic achievement may also be negatively impacted by responsibilities "outside of the college environment" [1], such as work or family, which may distract students from their academic studies. A large family size and a crowded household may also affect student learning [12].

Certain personal attributes also contribute to student success. Results of a survey conducted by $\mathrm{Gu}$, Schweisfurth, and Day [10] indicated that a majority of students perceived that selfdetermination was a factor of student achievement in EFL students. Donelly, McKiel, and Hwang [6] found that determination, perseverance, and resiliency were common characteristics of successful ESL nursing students. In the United Arab Emirates, it was noted that "having a positive attitude towards university also had a positive effect on the students' overall performance" [12].

The results of our literature review found that little research has been conducted on academic success in the Middle East. Due to this gap in the literature, we conducted a research study with funding from the Qatar National Research FundUndergraduate Research Experience Program. The research question guiding this study was: What are the perceived obstacles and motivators to student success in a post-secondary EFL setting in Qatar? The objectives of this research were to: identify barriers and strengths to student success in an academic setting; gain a better understanding of how to meet the educational needs of the students enrolled at our educational institution; and improve the overall academic environment at our institution.

\section{Methodology}

For the purposes of this research, we chose to modify the grounded theory approach to allow for informed initial data collection as suggested by Thornburg [16]. Grounded theory is a well-known qualitative theory that was developed by Glaser and Strauss in 1967. They describe this method as "the discovery of theory from data systematically obtained from social research" $[8,9]$. Our research is focused on the social phenomenon of the students' success while attending a post-secondary institution. As previously described, there is a gap in the literature regarding the understanding of the student perception of academic success in the Middle East and specifically in Qatar. The lack of research on this topic made grounded theory an appropriate methodology for this study. Grounded theory research suggests that the development of a theory related to the data be developed without a priori knowledge [9]. Frassinger clarifies that "the purpose of a grounded theory approach is to generate theory that is grounded in data regarding participants' perspective for a particular phenomenon" [7]. For our study, however, an initial literature review was completed in order to develop a basic understanding of the topic was a requirement for the funding proposal. After the initial literature review was conducted, the research team was modified to include two new faculty researchers as well as of six undergraduate students. Due to the new researchers' limited understanding of the literature review, the risk of data-sensitizing was mitigated. The general characteristics of this methodology are: 1) simultaneous data collection and analysis; 2) pursuit of emergent themes through early data analysis; 3 ) discovery of basic social processes within the data; 4) inductive construction of abstract categories that explain and synthesize these processes; 5) integration of categories into a theoretical framework that specifies causes, condition and consequences [5].

As was appropriate for our methodology, we undertook a cyclical approach for data collection and analysis. This approach included an initial convenience sampling of interviews to determine the validity of the interview and focus group questions and revise accordingly. After analysis, further sampling was completed until theoretical saturation was achieved at which time coding and analysis were completed and a theory was developed organically from the data.

The setting of this research was at an international branch campus of a Canadian university located in the Middle Eastern country of Qatar. This university specifically provides both undergraduate and graduate education in Nursing based on Canadian accredited curriculum. Recruitment for this study was focused on students who were enrolled in the Bachelor of Nursing program in the 2015-2016 academic year.

Prior to beginning data collection, ethical approval for this research was obtained from the University of Calgary Research Ethics Board. A convenience sample was drawn from the student population at the University. We purposefully sampled students that met specific criteria $[1,2]$ : age 18 years or older, enrolled in the regular track program. These students voluntarily participated in an audio-taped interview; and signed informed consent. In total, 35 participants were recruited for individual interviews and focus groups. Interviews were conducted by two student researchers, and data was recorded and transcribed. Data collected was simultaneously analysed as is consistent with our 
methodological approach [16] Coding and thematic analysis of data followed a cyclical process of constant comparison [6, 10], which was used to guide in the development of themes. In-vivo codes were modified into constructed codes which were then used to develop initial themes. A relational comparison approach [11] was used to review the themes, and creating visual representations of the themes allowed for the emergence of the final themes from this research.

\section{Results}

Overall, 35 students participated in individual or focus group interviews. Four of the participants did not complete the demographic information form. Of those that did, 22 were female, and nine were male. Most students were in the third or fourth year of their studies. Their ages ranged from 18 to 40 years old, with a majority of participants less than 25 years old. A variety of language groups were represented; first languages spoken by participants included Arabic (20), Somali (3), Tagalog (2), Pashto (2), Malayalam (1), Bahasa (1), Bravi (1), and Spanish (1). Family sizes were generally larger, with most participants indicating an average size of six or more people in the household (21).

Data analysis identified fifteen initial themes that were narrowed into four broad categories. Researchers further analyzed the data and the core themes of balance and passion emerged.

\subsection{Broad themes}

Throughout the cyclical analysis of the data collected many obstacles and motivators to student success were identified. The broad themes into which this data was consolidated into include: culture and language; personal attributes; academics; and social support networks.

4.1.1. Culture and language. Students in this study were primarily Arab descent, from a variety of countries across the Middle East. In general, students viewed culture as both a motivator and obstacle to student success. Students appreciated studying in a multicultural setting and being surrounded by different languages and cultures, both of which motivated them. However, some also commented on the importance of family in Arab culture and that family responsibilities and commitments may take time away from studies. In particular, students noted taking care of siblings and family events as being time-consuming commitments that could interfere with their studies. "For me, it's like family can make or break you...they need you sometimes, and that takes time out of your day." FG-4, 22.42. This may be particularly true for our study body, who tend to have large families as exemplified in our demographic information above. A large family also makes it more problematic to be able to find a quiet space within the home to study. One student commented: "My family issue, or problem, at home cannot make me focus or study at home" FG-3, 06.06. However, family also motivated students to work harder and achieve more. Some students entered nursing in order to provide economic stability for their family in the future. Some spoke of motivation from the perspective of caring for aging parents, while other students highlighted the desire to care for their future progeny. "The long-term motivation is to have a stable job, especially in this economic recession in the world, to have a successful career, and to maintain a family" FG-4, 17.06.

Within the classroom, cultural differences between students and instructors could affect learning. Several students commented that many of the new instructors, all of whom are Canadian, know little about the students' culture, which sometimes leads to conflict and misunderstandings. One student explained: "If I have a gathering or I have a wedding or something, can prevent me to do my work in the same day. Most of the instructor do not understand and they need to" FG-2, 27.10. Our campus has a relatively high faculty turnover rate. The students also observed that when new instructors first arrive, it takes them time to understand the student culture. "They should first know our needs what we need and to understand exactly about our culture because, really, most of them don't know our culture" FG-2, 21.38. Students noted that by the time these instructors begin to understand the students' cultures, they are leaving and being replaced by new faculty members. This continual turnover can be a source of frustration for the students as it can lead to friction and misunderstandings between faculty and students, as highlighted i this quote: "Some instructor... don't know about that culture here in Qatar- they don't know about it. They are not excusing the students [from assignments]. So sure, the student, he will be depressed and he don't want to study. So, no success for the students." FG-2, 18.01 .

Although far less frequently cited than culture, some students noted that English language proficiency was a barrier to their academic success. Due to contractual obligations of the university with the government as well as English being the lingua franca in our multilingual institution, our university provides instruction and student support services almost exclusively in English Students commented that their lack of proficiency made it more timeconsuming to study, prepare, and write assignments. One participant explained: "I need to collect the thoughts, make the sentence - sometimes. It does 
make it hard for us. Even when you're writing your assignments, sometimes we have information, and other work (and) we cannot translate it into English." $F G$ 4, 38.12. Some students also suggested that it would be beneficial to have support services at the university available in their first language. "The environment, the instructors, the student service. We need all the care in the student service at least explain for them. We need Arabic." $F G-2,29.14$.

4.1.2. Personal attributes. Several students believed that procrastination and lack of time management skills hindered their academic success. It could also lead to stress, which caused them to feel even more demotivated. One participant stated: "I think stress and lack of motivation in some- yeah, a lack of motivation that will lead to procrastinating that affects success." FG-2, 33.43. In contrast, the more successful students claimed that their ability to manage time helped them to succeed in their academics.

Perseverance was noted by several students as being instrumental to their success. Despite some obstacles that may have prevented them from doing so, they were able to persevere and succeed. Students who had an end goal were more likely to focus and persevere. This is highlighted by one student's statement: "If you really want to do something, if you're really passionate about doing that something, no matter how many times you fail it, if you keep on insisting that you will get the right thing and continue to do it over and over again. " I-4, 2.56

4.1.3. Academic environment. The academic environment also played a role in student success or lack thereof. In particular, the heavy workload was noted to be a barrier. Some students complained that there were too many written assignments, which they felt would not ultimately help them in their profession. The students perceived that the overload occurred because of curriculum issues, time management issues, and to a lesser degree issues with language proficiency. "The workload of the curriculum... I don't just want to study. I want to learn and gain the knowledge and not being able to do that demotivates me and is a barrier. "FG-1, 22.20

Students noted that some instructors were instrumental to their success. Students stated that instructors cared about the students and that they were knowledgeable about their subject, and this motivated the students to work harder. "For me, I think mostly, the instructors motivate me a lot because-- specific instructors, obviously, not all. Because they gave me a reason for doing it, and they-- the way of them teachings is really good." $F G-3$, 16.27. However, a few students commented that some instructors did not care about teaching, and they were viewed as unfair with regards to policies and grading.

Other aspects of the university environment also affected student success. Students felt that they had ample support within the institution, such as access to writing center specialists and a student counsellor, which helped them in their studies. One participant noted: "I think one of the things that leads me to be successful is the instructors. That they're really supportive, and they really motivate us to become better. Also, the facilities - that you have counselors that is available for us, if we need to talk to someone." FG-3, 20.16. Another student noted: "If I have a problem with my studying, or my learning, or if I have family issue, people here at the university: friends, or instructor, or whatever who work here trying to support. They are very flexible with everything. Really, that's why I like the environment here." I-3, 5.5.

Despite these resources, however, students felt that the lack of extracurricular activities on the campus was an obstacle to their success. The university offers only a limited number of extracurricular activities. Students commented that more access to such activities would benefit them by allowing them an opportunity to socialize and enjoy themselves. They believed that these opportunities would allow them to maintain more balance in their lives, which would reduce stress.

4.1.4. Social support network. Social support networks were instrumental in helping students to maintain their motivation. Their peers offered moral and study support for them as well as competition, which motivated them to work harder. One student stated that "since I got to (the university) I saw almost all the students are interested in learning and learning more. So this promotes me to study also, and also the good student around me, they study hard so it promotes me to study hard also. " I-2, 9.35

Friends outside of the university also helped the students to work harder, but at the same time, some students were pressured by their friends to socialize more, which could impede their studies. Similarly, families were supportive of the students and encouraged them, but family obligations and commitments such as weddings, holidays, and family gatherings often interfered with course work, which hindered their learning as mentioned above. Overall, a network of support systems led to students developing a love of their academic program: "The environment here is very good for me. Everyone is trying to help me, support me, including the instructors and students that I don't know. So I am enjoying the nursing now." I-3, 1.41 . 


\subsection{Core themes}

After having analyzed the data and identified themes, we discovered a common thread among culture, personal attributes, academic environment, and support networks. From this thread emerged the two core themes: achieving balance and following goals and passion.

4.2.1 Balance. The subtext throughout a majority of the interviews and focus groups included the fact that students who were able to balance their time between their studies, family commitments, social life, and work commitments were more likely to feel successful. Less successful students were far more likely to identify workload as an obstacle to their success. They appeared less able to maintain a healthy balance between their responsibilities.

Balance was achieved primarily by students' ability to manage time in order to have time for fun and social activities. The ability to set goals and manage time enabled students to successfully complete their assignments as well as have a fulfilling social life. Although they may have to decline some social invitations, they recognized the importance of having that time to alleviate stress. If a student could successfully manage their time, that allowed them the opportunity to spend time with friends and family, which reduced their stress and ultimately allowed them to work more effectively and generally be happier. One student explained: "Having a balance to be as a student, and as a mother or sister, and taking care of your family. It's also mean that you have to work hard to be able to successful, but enjoy your life also, at the same time." FG-3, 10.27. Peer support also offered a balance in students' lives. By collaborating, teaching each other, and offering moral support, students felt less stress and more balanced. Therefore, they were able to work more effectively and efficiently.

Balance also played a role in relationship to culture. Students' primary complaint against instructors was their lack of understanding of the differences between Canadian culture and of the student population's dominant Arab culture. The instructors who students found the most successful were those who understood the culture. However, this cultural understanding is impeded by the shortterm contract nature of employees at the university, leading to many instructors who only possess an elementary understanding of the Arab culture. However, as noted by one of the student researchers, not only is it important for the instructors to understand and adapt to the students' culture, but as it is a Canadian university, the students must learn and adapt, as well. A balanced understanding between the two groups may lead to greater academic success.
Balance as described by the students can be epitomized by the following quote: "Being able to manage your stress when you're doing your school work. Managing your time, again between your school life and social life, and having that balance which is really hard to find. " FG-3, 10.10.

4.2.2. Goals and passion. In addition to balance, another core theme that emerged from the data was having a passion and purpose for learning. A majority of the students who identified themselves as successful had a strong passion to become a nurse. Several students identified that they were "actually enjoying what [they] do, studying what [they] do, following [their] passion." FG-2, 6.10. Some students had been inspired to become nurses because of sick family members, so becoming a successful nurse had real value for them. One student stated: "For me what motivates me to study at (the university) is actually myself and my mom- she is sick. That's what actually motivates me to study and become a good nurse to take care of myself and others who need help. " $F-G-2,21.59$. As previously noted, if you have the passion for doing something you love and for learning, you have a passion for life.

Some students explicitly stated that creating and meeting goals helps them to succeed. One student said that she does the following: "set up a plan, organize your time for each subject. Set up a goals, basically, so we can work hard to reach that goal, so that's what I'm doing" I-1, 5.12. Another student described her motivation as being interconnected with the people around her, stating: "The surroundings, the friends that I have - they're passionate about learning and academics as well. And I think that's a very good thing, because I don't want to be around friends or people that do not have a goal set, or they do not have a reason for doing something. I want to be around people who are passionate about doing what they're doing. That's a good thing for success as well, for the motivation" I-4, 8.16. Not only do her own goals help her to succeed, but also the goals of her peers affect her motivation. Other students, as well, noted that their classmates' enthusiasm for academics and nursing were contagious.

Although many of the students had not originally considered nursing as a career choice, once they started taking clinical courses, they fell in love with the profession. They eagerly anticipated a time when they could use their education in real-life practice to help patients. Being motivated to learn because of having a purpose to know and understand the material was also a common belief among the students. Many students agreed with the student who stated: "Nursing is the passion that gives me strength and motivation to work like I work." I-4 5.29. When 
comparing their education in high school and university, students noted that previously they simply focused on memorizing and grades, but in university they focused on learning because what they learned would ultimately determine their success in their career. It motivated them to work harder and, consequently, be more successful. One student stated: I actually liked nursing, so it gave me a purpose of studying. There is a reason why I'm studying nursing because I love it, and I like to help people. That's what helped me be successful in my studies." F-G-3, 31.40. Another student noted the gravity of the profession of a nurse as a driving force to success: "Because you're going to deal with people's lives later, and their lives are going to be in your hands. So if you don't know your stuff, you're not just messing with yourself. You're messing with other people's lives, and that's a huge responsibility." FG-4, 33.47

\section{Discussion}

The results of our research both align with the published literature as well as add new insights into student success. The cultural understanding of instructors and students and the differences between these two groups may impact student success. Donnelly, McKiel and Hwang [6] discuss the difference between learning styles and teaching methods as well as instructors' awareness of students' cultural needs as impacting success. Similarly, our students highlighted that instructors who had been employed at the university longer and had greater understanding of culture better supported the students' cultural and academic needs. However, much of the literature also indicates that language proficiency prevents academic success $[6,14]$, which we did find but to a much lesser extent. Few students in our study stated that their lack of English proficiency impacted their learning. However, many of them did state that their course workload was a barrier. They primarily blamed the workload on their instructors and the curriculum. It is possible that the workload seems particularly onerous to the students because of their English skills. In particular, perhaps their workload was particularly burdensome because the readings were in dense, academic English that was difficult for the students to understand. Understanding the material in order to take tests and write papers would be particularly time-consuming for non-native English speakers.

The cultural dynamics of a family is also identified in the literature as a factor affecting academic success. By supporting students, the family plays a positive role, yet a family can negatively impact success because of family commitments and a large family size [12]. Our research also highlighted the fact that students felt that their family played both a positive and negative role in their achievement of academic success.

$\mathrm{Gu}$, Schweisfurth and Day [10] outline the importance of student self-determination as a key factor to students' achieving success. Harb and Elshaarawi [12] further suggest that having a positive attitude and active participation in class leads to academic success. Our results also highlighted the importance of self-motivation of the students as well as motivation from family and peers as being a key indicator to student success. In their meta-analysis on understanding self-beliefs and academic achievements, on the other hand, Valentine, DuBois, and Cooper [17] identified that student self-beliefs play only a marginal role in determining student success. This difference would be an interesting area for further research with our study population. We would postulate that the differences stem from cultural nuances of the populations studied, as their meta-analysis did not include studies on Arab culture within the Middle East.

The academic environment has been identified in the literature as a factor affecting student success $[4$, 8]; this is consistent with our research findings. Baker and Robnett [1] identified that students who were not involved in extracurricular activities were less likely to be successful in their academic careers. Several students in our study identified that they would welcome more extracurricular activities and that a lack of them decreased their motivation. Increased emphasis on extracurricular activities may lead to increased student success and retention.

The support of peers, family, and instructors motivated students to achieve academic success [6]. Peers have been identified as both moral and academic support according to Donnelly, McKiel, and Hwang's study [6]. Examples of academic support by peers include "answering questions, proofreading papers, correcting pronunciation, sharing concerns, and 'debriefing stress' and negative emotions" [6]. Similarly, our students identified all of these factors as contributing to their academic success.

The core themes of balance and passion that we identified in our study were not as explicitly identified in the literature as those listed above, but they are identifiable in the subtext of both the published literature as well as our results. For example, Hill, Lonas, and MacGregor [11] explain that when students can relate knowledge to their practice, they are more satisfied with their learning. This satisfaction with learning led to engagement with content [11]. This concept is similar to what we have identified as passion. Similarly, although it was not explicitly stated in the studies, the personal attributes of self-determination and positive attitude may be linked to purpose. 
A visual representation (figure 1) was created in order to depict our findings of the project.

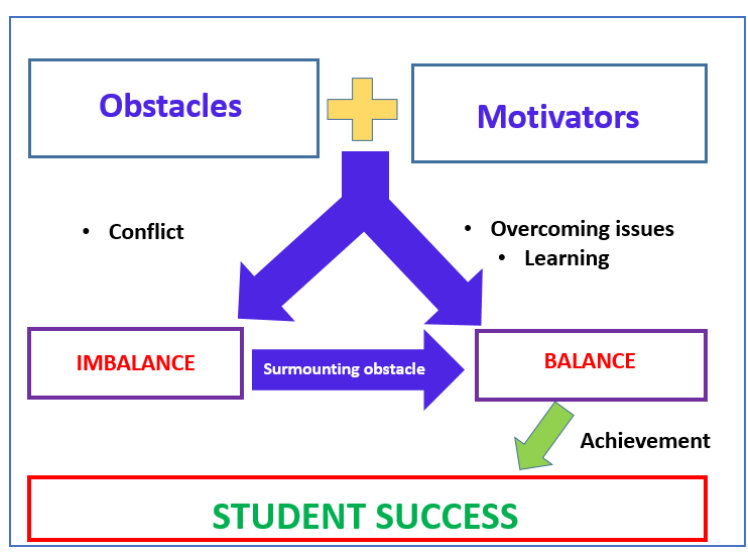

Figure 1. The path to academic success

As previously discussed, our core themes could be interpreted as both obstacles and motivators to student success. Culture, personal attributes, academic environment, and social support networks could all either hinder or accelerate success. How a student responds to each affects their ultimate success. Students who already have well-developed personal attributes, such as perseverance and the ability to manage time, are more likely to be able to overcome learning issues and, therefore, achieve balance. These students are better able to focus on their education as well as have the opportunity to socialize and manage family responsibilities. Because these students experience more balance between their various roles, they tend to be more successful. In contrast, students who lack such abilities may be more likely to experience conflict, which could prevent students from becoming successful. These students appeared more likely to experience stress and to become demotivated. However, students who are passionate about learning and the profession and can create personal and academic goals for themselves appear to be better able to surmount these obstacles and achieve success despite their shortcomings. They were better able to find the motivation to overcome their individual learning issues.

We propose that student success is a complex, culturally linked, multifaceted phenomenon. Our research identified that students without passion for their field of study did not identify themselves as being as successful in their academics. Balance in a student's life was also identified in the results as instrumental in leading to leading to success.

\section{Strengths and limitations}

The use of student researchers during the data collection and analysis process strengthened our study. Student participants may have felt more comfortable with their peers and consequently been more honest in their responses. Student researchers were also able to provide us with greater insight into the data. Data checking informally occurred by having students as members of the research team. Rich data collection occurred due to comprehensible interview and focus group questions; however, had the researchers conducting the interviews been more experienced, even richer data may have been collected. A limitation to this study was the single academic setting for data collection, thus reducing the generalizability of findings to other settings.

\section{Recommendations}

Based on our findings, we recommend that international branch campuses offer cultural training courses or workshops to new faculty. It would also be beneficial for new students to learn and understand about the differences in the expectations and culture of the home country of the institution. This shared learning between faculty and students would lessen gaps between the cultures and promote greater cultural understanding, leading to student success.

Adaptations to the academic environment, such as resources related to time management, would also help students succeed. As our participants suggested, university support services could be offered in students' native language to help them navigate the labyrinth of academia and enrich their university experience. Counselling services and student support groups should be available to students who are feeling overwhelmed with the workload or the lack of balance in their lives. Universities can further promote balance within the academic environment by providing students with opportunities to participate in extracurricular activities and social events.

The determining factors related to student success of EFL students in higher education in the Middle East as well as other regions of the world should be further examined. As the findings from this study cannot be generalized, it is recommended that research about student success be conducted in a variety of disciplines.

\section{Conclusions}

This study used grounded theory to explore the factors that lead to student success in an international branch campus in Qatar. An analysis of the data 
revealed two core themes: achieving balance and having a passion. A variety of obstacles and motivators affect student achievement. If these obstacles and motivators can be balanced, students are more likely to experience success. Students who cannot balance them often experience stress. Passion for a subject and a career gives students a purpose for learning, which motivates them to work harder. Students who can both balance the obstacles and motivators as well as understand the purpose of their learning are the most likely to see themselves as successful.

\section{Acknowledgement}

This research paper was made possible by UREP grant \# 18-134-3-029 from the Qatar National Research Fund. The statements made herein are solely the responsibility of the author[s].

We acknowledge the contributions of: Nazanin Ahmadi, Hind Al-Amri, Mihirani Chandraratne, Alka Cherian, Maria Baluya, and Sarah Fatah.

\section{References}

[1] Baker, C. and Robnett, B. (2012). Race, social support and college student retention: A case study. Journal of College Student Development. 53(2), 325-335. DOI: $10.1353 /$ csd.2012.0025

[2] Ballantine, J., and Hammack, F. (2009). The sociology of education: A systematic analysis $\left(6^{\text {th }}\right.$ ed.). Upper Saddle River, NJ: Prentice Hall.

[3] Bolderston, A., Palmer, C., Flanaga, W., and McParland, N. (2008). The experiences of English as second language radiation therapy students in the undergraduate clinical program: Perceptions of staff and students. Radiography, 14, 216-225.

[4] Charmaz, K. (2005). Grounded Theory in the $21^{\text {st }}$ Century: Applications for Advancing Social Justice Studies. In Denzin, N.K., \& Lincoln, Y.S. (Eds.), The Sage Handbook of Qualitative Research (3 ${ }^{\text {rd }}$ ed.), 507-535.

[5] Charmaz, K., and Mitchell, R. G. (2001). Grounded theory in ethnography. In P. Atkinson, A. Coffey, S. Delamount, \& J Lofland (Eds.), Handbook of ethnography, 160-174. London: Sage.

[6] Donnelly, T. T., McKiel, E., and Hwang, J. J. (Sep 2009). Challenges and motivators influencing the academic performance of English as an additional language (EAL) nursing students: The perspectives of the students. CJNR: Canadian Journal of Nursing Research, 41(3), 130-150.

[7] Frassinger, R.E. (2005). Paradigms, praxis, problems, and promise: grounded theory in counseling psychology research. Journal or Counseling Psychology, 52, 156-166.
[8] Glaser, B. G., and Strauss, A.L. (1967). The discovery of grounded theory: Strategies for qualitative research. Chicago: Aldine.

[9] Glaser, B. G., and Strauss, A.L. (2011). The discovery of grounded theory: Strategies for qualitative research. New Brunswick, U.S.A.: Aldine Transaction

[10] Gu, Q. Schweisfurth, M., and Day, C. (2010). Learning and growing in a 'foreign' context: intercultural experiences of international students. Compare: A Journal of Comparative and International Education, 40(1), 7-23.

[11] Hill, Y., Lomas, L., and MacGregor, J. (2003). Students' perceptions of quality in higher education. Quality Assurance in Education, 11(1), 15-20.

[12] Harb, N. and El-shaarawi, A. (2007). Factors affecting business student's performance: The case of students in United Arab Emirates. Journal of Education for Business, 82(5), 282-290. DOI: 10.3200/JOEB.82.5.282-290

[13] Li, H., Fox, R. F., and Almarza, D. J. (2007). Strangers in Stranger Lands: Language, Learning, Culture. International Journal of Progressive Education, 3(1), n1.

[14] Jeong, S. Y. S., Hickey, N., Levett-Jones, T., Pitt, V., Hoffman, K., Norton, C. A., and Ohr, S. O. (2011). Understanding and enhancing the learning experiences of culturally and linguistically diverse nursing students in an Australian bachelor of nursing program. Nurse Education Today, 31(3), 238-244.

[15] Sanner, S., and Wilson, A. (2008). The experiences of students with English as a second language in a baccalaureate nursing program. Nurse Education Today, 28, 216-225.

[16] Thornburg, R. (2012). Informed Grounded Theory. Scandinavian Journal of Educational Research, 56(3), p. 243-259.

[17] Valentine, J., DuBois, D., and Cooper, H. (2004). The relation between self-beliefs and academic achievement: A meta-analytic review. Educational Psychologist, 39(2), 111-133. 